\title{
Rural EFL Teachers' Emotions and Agency in Online Language Teaching: I Will Survive
}

\author{
Dini Rosita Sari* \\ Sekolah Menengah Atas Negeri 1, Nunukan, North Kalimantan - Indonesia
}

\begin{abstract}
This article explores rural English as a Foreign Language (EFL) teachers' emotions and agency in online language teaching. Based on Hargreaves's emotional geography framework, teachers' emotions and teacher agency are both captured through teachers' narration about their feelings, salient challenges that they encountered, and their coping strategies. Research data were collected using semi-structured interviews with two English teachers working in rural upper secondary schools in Nunukan, Indonesia. The collected data were analyzed with an inductive approach. The findings portray how rural EFL teachers experience various emotions which are mainly caused by physical and sociocultural distance, how agency helps these teachers with abilities to reflect on their feelings and to take crucial actions, and to what extend the need for immediate professional development programs to develop online teaching skills is.
\end{abstract}

Keywords: Online language teaching; rural teachers; teacher agency; teacher professional development

\section{Introduction}

The emergence of digital technology has brought changes to how English is taught. For example, Kozar (2012) reported the use of synchronous online tools in English language teaching in Rusia. A more recent study investigated how online collaborative writing was done using computer-mediated learning communication (Such, 2019). The results

\footnotetext{
${ }^{*}$ Corresponding Author: Dini Rosita Sari
} (dini.rositasari@gmail.com) Sekolah Menengah Atas 1, Nunukan Regency, North Kalimantan 77482 indicate the need for special curriculum designed to promote collaboration between language learners. Various practices of online language teaching have also been found across the globe, for instance, online English language learning via e-mail correspondence between American and Taiwanese university students (Cifuentes \& Doris Shih, 2001) and the implementation of urban gaming as a tool for teaching English in upper-secondary schools in Poland (Pitura \& Terlecka-Pacut, 2018).

Aside from the application of technologies in language classrooms, rural teachers already have their concerns. Take, for example, 
teachers in rural USA, as noted by HansenThomas et al. (2016), face challenges in teaching English such as students' mastery of academic vocabulary, students' unwillingness to ask questions or speak, parents' little supports for their children's education, and teachers' short times for teaching and lesson planning. In a different case in Thailand, the language curriculum which gives little attention to rural teachers' voices in the process of designing has also become a problem for rural teachers (Hayes, 2010). This absence of representation, of course, has an impact on the application of the curriculum in rural settings. Meanwhile, looking beyond the classroom, the role of English teachers in mediating sociocultural issues in rural settings has also contributed to the issues (Fogle \& Moser, 2017). The study reported two important points; rural teachers were "dealing with discriminatory stereotypes about racial, ethnic and linguistic difference that permeated their work with students and colleagues" (p.9) and concerns about systemic curricular, roles in schools, and teaching skills.

English as a Foreign Language (EFL) teachers in rural Indonesia face similar problems. As reported by Febriana et al. (2018), teachers in rural Indonesian schools deal with inadequate infrastructure such as electricity supply (Anwar et al., 2020), lack of learning sources, local language barrier, absence of parents' supports, teachers' competencies and students' learning performances and motivation. This finding is supported by a recent study investigating the difference between urban and rural students' attitude in learning English (Wigati, 2019). The results show that the number of rural students who enjoy learning English is 12\% lower than that of urban students. Meanwhile, Kam (2002) highlights the practice of English language teaching in East Asia, particularly in Indonesia. He emphasizes that, despite the fact that students are taught well in urban primary schools and private schools, English was not included in the time-tables in primary schools in rural areas. Consequently, students start learning English in junior high schools. Hence, the low English performance shown by these students by the time they enter senior high schools becomes a problem for the English teachers. Finally, there is also another problem such as the geographical condition which contributes to inequal access to facilities and infrastructures (Rejeki et al., 2018). With such a problematic situation, it could be understood that rural EFL teachers have constraints that are different from those encountered by teachers in urban areas.

With the outbreak of the Covid-19 pandemic and EFL classes suddenly transferred to a virtual setting, EFL teachers in rural areas of Indonesia struggle to perform their professional responsibilities. Lestiyanawati and Widyantoro (2020) put the blame on teachers' lack of competence in operating digital tools, schools' inadequate facilities regarding online teaching, and students' disadvantaged background and inability to assess the internet. Moreover, teaching in an online setting needs different approaches and thus requires teachers to have different skills (Hampel \& Stickler, 2005). Together, all these issues surrounding rural EFL teachers during online language teaching have become the main source of their constraints and eventually made teaching more challenging than ever. In consequence, rural teachers may experience various emotions, both negative 
and positive, during the teaching and learning process, which make up the 'emotional geographies' of teaching, as proposed by Hargreaves, which cover (1) physical geography that refers to the emotions affected by time or space, (2) moral geography that refers to the emotions affected by sense of professional accomplishment, (3) sociocultural geography that refers to the emotions created by difference of gender, race, ethnicity and culture, (4) professional geography that represents the emotions created by different understandings of the professionalism norms, and (5) political geography that refers to the emotions affected by different understandings of power (Hargreaves, 2000, 2001a, 2001b, 2005).

Hargreaves (2001a) clarified that teaching is "inextricably emotional-by design or by default" (p.1057). Therefore, emotion is viewed as an integral part of teaching which could not be separated from teachers. Teachers' emotions could affect their relationship with students, colleagues, and parents (Hargreaves, 2001a). Hence, one way to establish successful teaching and learning, as highlighted by Hargreaves (2001a), is that teachers should possess a fine emotional understanding manifested in the forms of emotional geographies.

However, in EFL teaching, studies on emotional geographies are still limited. Liu (2016) investigated how a non-native English teacher dealt with emotional experiences in England. Another study reported the emotional feelings of an EFL teacher in Japan (Cowie, 2011). The result of the study indicates the need of thorough discussion on teachers' emotions and moral purpose of teaching English. A more recent study investigated the emotions of a female English teacher in rural area in Indonesia (Rejeki et al., 2018). The result shows that sociocultural disparities, particularly in cultural background and religion, make the teacher feel uncomfortable in performing her job. In summary, all these studies together provide evidences of the complexity of teaching English in rural areas, especially in face-to-face classroom.

While the notion of emotional geographies are discussed to make sense of teachers' emotions that are likely caused by the distance in various aspects of schooling, teacher agency has received attention because of its possibility to enable teachers question their current practices and take action under the problems they encounter (Liu et al., 2020). Agency, as what Rogers and Wetzel (2013) claim, is "the capacity of people to act purposefully and reflectively on their world" (p. 63). In order to define teacher agency, Priestley et al. (2012) point out that agency can be achieved with the influence of formal education, professional and personal experiences, and can occur in particular concrete situations. To support the argument, Biesta (2011) highlights that teacher agency is considered as an achievement rather than a mere capacity, since it requires cultures of thinking and practices. In other words, it can boldly mean that agency needs to be earned rather than titled.

Investigation on teachers' agency becomes prominent since teachers' positive attitude toward instructional conditions only occurs when they enact agentive roles throughout their teaching practices (Kayi-Aydar, 2015). By exercising agency, teachers will have the courage and ability to make decisions which will benefit their students (Molla \& Nolan, 2020). In 
the context of online language teaching, teacher agency can help teachers to deal with the unexpected emotions that happen while conducting their language lessons online. By understanding how these teachers exercise their agency, we can learn about the strategies that they adopt to solve problems at hand to make their online teaching more effective.

Given the aforementioned problems, uncovering rural EFL teachers' emotions and agency provide beneficial inputs for rural English teachers across the country who might be under similar circumstances. The present study also has essential implications for professional learning programs for rural teachers, especially in online teaching.

\section{Method}

Based on Hargreaves's emotional geography framework, this qualitative study implemented a narrative framework to explore the emotional lived experiences and agency of two rural secondary school English teachers in Nunukan in North Kalimantan. To be more precise, interview-based qualitative research and narrative inquiry by Clandinin (2006) were adopted in order to make meanings of the stories told by the participants of the study. The participants reflected on their practices of online language teaching, identified the challenges they experienced, and narrated the strategies they adopted to deal with the issues.

\section{The Rural Areas}

As the research participants' narratives were influenced by the notion of rural areas, it is essential to present this notion in order to understand the context of the study. Nunukan is one regency in Indonesia that belongs to the frontier, outermost and least developed area, which is often referred to as $3 \mathrm{~T}$ (terdepan, terluar, tertinggal). The 3T regions are normally indicated by their slow development progress because of inadequate infrastructure, low quality of human resources, and unbalanced distribution of capital. In consequence, these three factors have contributed to the low quality of the schooling system, including schools in Nunukan. In English language teaching, the lack of interest and need to use English are also shown by rural students, thus making the job of teaching English in this 3T region become more challenging, which inevitably affects teachers' emotions.

\section{Participants}

Two teachers from upper secondary schools in Nunukan were eager to become the participants of this study. The researcher first approached several potential candidates through phone calls and requested for their participation. However, only two teachers agreed to take part in the study. These teachers were then asked to fill in a consent form which required them to share their personal data. The participants of the present study were recruited because of three main reasons: (1) they will share information about their perceptions of English language teaching in a virtual classroom; (2) they are familiar to the researcher and (3) they were actively teaching in rural secondary schools at the time of the study. These reasons enabled the researcher to communicate with both participants comfortably and collect the data more easily. 
Table 1

Participants' Demographic Information

\begin{tabular}{lllcll}
\hline Pseudonyms & Age & Sex & Teaching experience & $\begin{array}{c}\text { Education } \\
\text { Background }\end{array}$ & Degree \\
\hline Nurani & 30 & Female & 4 years & ELT & Bachelor \\
Intan & 30 & Female & 5 years & ELT & Bachelor \\
\hline
\end{tabular}

\section{Data Collection}

Semi-structured interviews were used to elicit the participants' viewpoints on English language teaching in an online setting. Before conducting the interviews, I, as the researcher, contacted both participants through WhatsApp messages to explain about how the interviews would be possibly done. Both participants finally agreed to have face-to-face interviews. The interviews lasted for approximately 45 minutes, conducted at different times, and took place at the participants' houses in the afternoon. Both interviews were done in Indonesian language. In order to make the participants felt more comfortable in sharing their viewpoints, the interviews were done in a friendly manner.

Prior to the interviews, I asked for the participants' permissions to record their answers by using a mobile device. The main questions asked were as follows:

1. How did you feel when teaching English online?

2. What challenges did you encounter when teaching English online?

3. What were your strategies to deal with these challenges?

\section{Data Analysis}

The collected data were transcribed completely and carefully, and then sent to each participant through WhatsApp messages. Both participants were encouraged to read and make correction by revising or adding more information in order to make the data as valid as possible before sending the data back to the researcher. The revised copies were then sent again to both participants for final checking and their approval.

For the purpose of this article, the data were then translated into English according to the following rules: (a) excluding everything that is out of the context of the questions, (b) including salient points in terms of content, (c) avoiding any personal judgments, and (d) keeping the actual wordings of the participants where possible (Adamson \& Meister, 2005). These data were later analyzed based on the recurring themes and patterns with an inductive approach (Braun \& Clarke, 2006). The viewpoints of the two participants were thoroughly identified in order to investigate these rural teachers' emotions and agency in online language teaching. The procedure of the data analysis was as follows. First, the translated data were read through several times to get familiar with it. Second, the data were then coded by highlighting phrases or 
sentences in different colors corresponding to other codes. Third, the codes were looked up carefully to identify themes and patterns. Fourth, the recurring themes and patterns were reviewed by comparing them with the data set in order to validate their accuracy. Fifth, the already accurate themes and patterns were defined in accordance with the emotional geographies theory by Hargreaves. Finally, the data showing the participants' emotions were then classified into positive and negative feelings.

\section{Findings}

Drawing on the interview data, the present study explores the emotions and agency of rural teachers regarding English language teaching in an online setting in secondary schools. The two notions were identified through the narration of both participants regarding their emotions during online language teaching, challenges encountered by participants, and their strategies to overcome those challenges.

\section{Participants' Emotional Experiences during Online Language Teaching}

The Indonesian government has applied distance learning since March 2019 in response to the Covid-19 pandemic. Schools across the country were closed down and students have been studying from home since then. The immediate change of how teaching and learning should be conducted during this Covid19 lockdown gave very little time to teachers to adapt and adjust their teaching materials, media and styles. In consequence, teachers experienced various emotions during the online teaching. English teachers in secondary schools in rural areas also had diverse point of views about teaching English in an online setting. Nurani and Intan went through some negative emotions that decreased their confidence as teachers. Before the lockdown, they conducted their classes in a face-to-face classroom setting. Hence, when they were required to move their classes to a virtual classroom, they felt disoriented at the beginning. As told by Nurani, she felt panicky and confused about how she might conduct her English class online:

At first I was panicky because lesson plans..media and materials...all were designed for traditional classroom. So, when Covid-19 stroke and classes were transferred to a virtual class I felt confused...not knowing where to start, just confused. So... yes, I was completely confused and wondered where to start what to focus first...completely confused. (Nurani, February $12^{\text {th }}$, 2021).

Regarding the change in the type of interaction and communication occurring between teachers and their students, Intan experienced a frustration. The students were passive and rarely responded to the instructions that she delivered through WhatsApp messages:

For example... the other day we talked about how to introduce ourselves in English. I asked the students to record their voices in WhatsApp voice notes. Very few students responded... and there were several students even said, "I really don't know English." So... I'm confused...how to teach English virtually? (Intan, February $13^{\text {th }}, 2021$ ).

As Intan teaches in an area more remote than the area in which Nurani teaches, several of her students live in a place with very limited access to internet connection. As a result, these students did not attend her classes which became another source of her concern:

Obviously I felt a bit frustrated because it was different from usual, especially at this time of the pandemic. And... Not interacting directly with the 
students makes it rather difficult for me to teach English virtually. That is in my opinion. Besides...some of our students live far away from the internet range which makes it a little frustrating. (Intan, February $\left.13^{\text {th }}, 2021\right)$.

Aside from online learning materials, since several students in her school had issues with the internet connection, Intan should also provide hard copies of the English materials for these students so that they can study independently at home. Having to supply two different teaching materials at the same time every week resulted in her burnout, as she described as follows:

About this online and offline teaching... I feel more tired. I have to prepare materials for students in both online and offline classes every single week. Not to mention writing a report of their attendances and marking their works. So, teaching in this situation makes me really tired. (Intan, February $13^{\text {th }}, 2021$ ).

Although both Nurani and Intan had hard times at the beginning of the online language teaching practice at their schools, they gradually perceived the situation in a more positive way. The shift of these emotions was because they realized that they could not avoid this issue and thus they needed to adapt themselves to this new circumstance. This acceptance enabled Nurani and Intan to later reflect on their experiences during the virtual classroom. Nurani, as she described below, had developed an internal motivation to learn how to conduct a virtual classroom:

Now it's getting better and better. I'm also getting used to it. Now I feel like I want to learn again and again so that I can improve my teaching. I am also motivated to learn how to manage a virtual classroom because we definitely can't use the same technique that we used to apply in conventional classroom. So, yeah...I want to learn more to get more information. Yes...l feel motivated and also challenged to di virtual teaching. (Nurani, February $12^{\text {th }}, 2021$ ).

The same motivation was expressed by Intan during the interview. She even felt more enjoyment about the situation:

My emotion changed, from being frustrated at first to trying to accept and understand. Clearly we (teachers) can't avoid this situation...so I as an educator have to improve my teaching method and skills so that I can deal with these children (students) in the virtual classroom. Now I feel more enjoy and challenged. (Intan, February $13^{\text {th }}$, 2021).

\section{Challenges Encountered by Participants in Online Language Teaching}

Teaching English to students at secondary schools in rural areas is challenging. With different culture, inadequate infrastructure, different parents' perceptions and lack of learning sources, English teachers in these areas face many problems. These issues have become even more complicated with the distance learning policy applied by the Indonesian government. Nurani and Intan had to teach English, which is a foreign language to students in rural schools by using digital tools and online learning platforms. Though enabling a virtual meeting between teachers and students, online teaching remains problematic for these teachers. Nurani told her story as follows:

There is a major difference. I think it is very drastic. First, we (teachers) don't know what to do... Because this is English, so we usually interact (with the students) directly, like talking directly, communicating directly, so with virtual, it's like... what's going on? Like there is a gap there. Even though we communicate through video conferencing, the students still don't get what I mean. It's disconnected. (Nurani, February $12^{\text {th }}$, 2021). 
Apart from external challenges, Nurani also reported an internal issue. She described her incompetency in operating digital devices and certain learning platforms resulting in her poor performance in teaching in a virtual classroom:

Like dealing with this digital technology...I personally have difficulties with operating digital devices. Sometimes these learning platforms require installation and so on and to keep it up to date... my gadget doesn't support sometimes. I am not really good at it. So, when I am about to teach and I get a problem, I am panic and confused. (Nurani, February $12^{\text {th }}, 2021$ ).

Intan had a problem dealing with students' lack of performance in English. In rural areas, students start learning English in lower secondary schools with limited additional courses outside the formal education. Therefore, the students' competence of English is far different from students in urban areas. With inadequate knowledge, students finally have difficulties in learning English materials offered by the secondary schools' curriculum. Intan considered it as a problem:

They don't seem to understand the basic knowledge of English. It becomes a bit difficult. Meanwhile...they have to study quite a complicated material in secondary schools, so that sometimes when I teach English in their class...they say: "sorry Ma'am, I don't know, I don't understand." (Intan, February $13^{\text {th }}, 2021$ ).

As students learn online from home, their presence at school was no longer a requirement. Therefore, it becomes harder for teachers to monitor their engagement in the learning process. This is where parents play an important role. Their supports for children's learning contribute to the success of the overall teaching and learning process during the pandemic. However, as Intan mentioned during the interview, parents' involvement in rural areas is still low:

We once visited a student because we never heard from him for such a very long time. When we listened to what the parents said...it seemed like they just didn't care. They didn't tell his son to go back to school or what...they just ignored it. (Intan, February $13^{\text {th }}$, 2021).

\section{Participants' Strategies in dealing with Challenges}

Nurani and Intan both had strategies regarding the emotional challenges that they experienced during the online English language teaching. Throughout the interview, they indicated that they finally accepted the circumstance and started to personally seek for solutions to their problems. Nurani turned to her colleagues at schools to get help with the digital device issue:

I talk to my colleagues and ask for help. And sometimes there's a problem with my gadget, I ask for help, too. And then okay I understand now, next time I can do it by myself. (Nurani, February $12^{\text {th }}, 2021$ ).

She also expressed her agency as a teacher in dealing with the problem. She looked for new sources of knowledge and teaching resources on the internet to improve her teaching skill and make her students become more attracted to the online classes. Nurani mentioned about the role of English teachers association in the regency, MGMP (Musyawarah Guru Mata Pelajaran), to help her cope with the confusion of teaching English online:

If I didn't do anything, I knew l'd feel depressed. So, slowly...I told myself, it's okay, it's okay..the teaching and learning process will still continue, but I have to do something about it. I have to learn to get new information and browse on the internet on how to make my online lesson 
interesting for my students. (Nurani, February $\left.12^{\text {th }}, 2021\right)$.

Ah...and the workshop conducted by MGMP the other day, I applied it in my classroom and my students started to be more active. It made me realize that I have to use different media while teaching in a virtual classroom, okay..I understand now, I will improve my knowledge again...like that. (Nurani, February $12^{\text {th }}, 2021$ ).

Similar to what Nurani expressed, Intan also mentioned the use of internet to help her find the appropriate methodology in English language teaching in an online setting. Her initiative to find solutions to all the challenges that she encountered received support from her association, too. She explained how the workshop held by the association had given her an idea on how to take her teaching to the next level:

I browsed. To overcome my anxiety about teaching English online, I browsed. I searched for information on how to teach English online and...try to find teaching and learning methods..or...like game, yes, like that. Then I used it to see whether the students liked it or not. (Intan, February $13^{\text {th }}, 2021$ ).

I admit that...uh...my skills in designing virtual classroom activities is still lacking. That's why when our MGMP conducted the online workshop on how to make interactive worksheets, I instantly utilized it in my English class. It helped a bit. It has made my class more interesting. (Intan, February $\left.13^{\text {th }}, 2021\right)$.

As the students' low competence of English also became a problem for Intan when conducting online English language teaching, she should come up with a practical solution. In the interview, Intan described how she had modified her teaching materials and adjusted them to the rural students' level in order to make it easier and more possible for her to deliver the English lesson:
That's why I don't teach what's in the curriculum... I modify it. (Intan, February $13^{\text {th }}, 2021$ ).

I then taught differently with what's on the book... I simplified it. For example, sometimes instead of teaching what's in the syllabus, I taught basic vocabulary...asking them to pronounce the words and to send their works through voice notes in WhatsApp. (Intan, February $13^{\text {th }}, 2021$ ).

\section{Discussion}

The findings of the present study provide insights into rural upper secondary school EFL teachers' emotions and agency when conducting an online language teaching during the Covid-19 pandemic. Both participants experienced similar negative emotions at the beginning of their online teaching practices namely panic, confused, frustrated and tired. Lundin (2020) pinpoints panic as an evitable defense mechanism when facing transitions in one's life. The feeling of Nurani and Intan was mainly caused by the sudden shift from face-toface teaching to online teaching. These rural teachers' negative emotions are can be predicted because implementing online language teaching in rural areas was very much unanticipated. As a result, in-service teachers who have inadequate skills and knowledge about digital learning tools experienced difficulties and hindrances in conducting their daily tasks.

The absence of intense interaction has reduced the student-teacher relationship (Hargreaves, 2001a), in particular in rural settings where both teachers and students have issues with groundbreaking technology. As described by Nurani, she sensed a disconnection from her online class since she felt that there was a gap between her and the students. Howland and Moore (2002) explained 
that this feeling of isolation is caused by the lack of face-to-face and real-time interaction. This insufficient interaction eventually contributes to other problems such as attrition issue and loss of motivation (Gigliotti, 2016), which become the cause of the decreased students' engagement. For the participants of this study, it has become a significant constraint since they hold on to a believe that teaching English should be done directly in face-to-face conventional classroom interaction.

A more critical discussion will be centered on students' backgrounds (students' competence and low motivation) as well as parents' lack of support which together serve as evidence of the sociocultural issue. The disparities in value and wisdom about English language teaching and learning have affected the emotions of rural teachers. Febriana et al. (2018) report that Indonesian rural teachers must deal with students who have little knowledge of English and ones who are less interested in studying the language. Socioeconomic status has been acknowledged as one cause. Students with less advantaged backgrounds, the lower parental education level in particular, tend to be less motivated in learning English (Iwaniec, 2020; Kormos \& Csizér, 2008; Lamb, 2012). As exposed by Intan during the interview, the student who was absent most of the time in her class has unsupported parents. It is particularly because rural parents who do not hold sufficient educational background tend to fail to see the potential of English in the global competition. Hence, they are not able to nurture their children's motivation to pursue English study (Iwaniec, 2014).
Despite the challenges, these rural teachers have shown evidence of teacher agency exercises through critical reflections on how they should respond wisely to their negative feelings (Miller \& Gkonou, 2018). They eventually chose to embrace their feelings, made meaning of them, and shifted their focus on how to find solutions for their problems instead of getting carried out. Both Nurani and Intan put efforts into gaining new knowledge about online language teaching from the internet and continuously seek for help from their colleagues who are considered more skillful. These positive attitudes enabled both Nurani and Intan to gradually feel more motivated and enjoy the current circumstance. They realized that their resistances to change would be a barrier in performing their jobs.

Ashton (2020) argues that novice teachers will try out different techniques that are tailored to their students' needs. It was clearly shown by Intan who has a five-year-experience of teaching when she decided to simplify the English materials to solve the problem regarding students' English low competence. It was based on genuine understanding and acknowledgment of her position as a learning facilitator in order to help students benefit from their learning. Intan has showed leadership, and as proposed by Jenkins (2020), a proactive agency, by personally choosing to plan for and start a change in her class. This is in line with what Molla and Nolan (2020) emphasize that the ability to make sense of feelings and be courageous to transform the current practice in the students' interests are proofs of teacher agency. This finding suggests that teachers should enact their agency as their continuous professional learning efforts (Molla \& Nolan, 
2020) in order to contribute to a better change in students' learning output (Fairman \& Mackenzie, 2012).

In their attempts to overcome the anxiety caused by the inability to set up good online learning activities, Nurani and Intan referred to the crucial role played by teachers association in rural areas. Since professional development is needed to keep rural teachers keep up with current trend and issues in language learning (Anwar et al., 2020), the program should be designed in accordance with rural teachers' characteristics as well as be made accessible for them (Hansen-Thomas et al., 2016) and delivered differently (Mpahla \& Okeke, 2015). Unlike teachers in urban areas who may feel more confident in joining trainings or workshops conducted by a wide-scale organization, teachers in rural areas may find it more comfortable to learn within their grassroots organization as expressed by Intan as follows:

Even though both trainings bring benefit...but I feel more comfortable learning within our district teachers association because it feels more personal and it suits my situation. (Intan, WA messages, February $20^{\text {th }}, 2021$ ).

Various forms of professional development programs could be constructed by the district teachers forum. In online teaching, rural teachers particularly need to be trained 'in basic ICT use, software-specific application, and the affording of the medium' (Hampel \& Stickler, 2005). Professional development programs should take into consideration the necessity of facilitating communication and interaction in online setting (Compton, 2009; Hampel \& Stickler, 2005). This essential online teaching skill will help rural teachers to design class activities that promote students' communication in the virtual classroom, which will help reduce teachers' worries.

\section{Conclusions}

This paper portrays rural EFL teachers' emotions and agency in online language teaching. They first experienced panic, frustration, confusion and burnout during online language teaching. For these teachers, the main constraints are the physical distance and the sociocultural aspects, namely students' low motivation and lack of parents' support. Recognizing their resistance could be a drawback, these negative feelings gradually changed and replaced with joy and motivation. Finally, the notion of professional learning effort was discussed. Rural teachers expressed their appreciation for the training conducted by grassroots teachers association since it helped them develop essential basics for online language teaching.

The study presented in this article has some limitations. The participants recruited for this study included two female teachers with similar characteristics (age, gender, and length of teaching experience). Distinct characteristics could be useful in order to gain various data so that the findings would be richer in order to understand the problematic situations experienced by rural English teachers during online teaching. Likewise, this study relied on the data that were collected solely from semistructured interviews. Future research could include quantitative data that are gathered through surveys or questionnaires and invite more participants in order to generalize the findings to the wider population. Finally, this study has implications for understanding thoroughly the emotions and needs of rural 
English teachers while teaching online. It calls for immediate and continuous professional development programs which are designed and held by grassroots organization to help rural EFL teachers develop skills for effective and efficient online language teaching, as well as to nurture teacher agency.

\section{References}

Adamson, L., \& Meister, D. G. (2005). Teachers' knowledge about adolescents: An interview study. Scandinavian Journal of Psychology, 46(4), 343-348. https://doi.org/10.1111/j.14679450.2005.00464.x

Anwar, K., Faruq Ubaidillah, M., \& Sulistiyo, U. (2020). Exploring EFL teachers' classroom management: The case of Indonesian remote secondary schools. Journal of Language and Education, 6(3), 22-35. https://doi.org/10.17323/jle.2020.10549

Ashton, K. (2020). Novice teacher agency in the multi-level language classroom. Language, Culture and Curriculum. https://doi.org/10.1080/07908318.2020.18 18766

Biesta, G. (2011). From Learning Cultures to Educational Cultures: Values and Judgements in Educational Research and Educational Improvement. International Journal of Early Childhood, 43(3), 199-210. https://doi.org/10.1007/s13158-011-0042-x

Braun, V., \& Clarke, V. (2006). Using thematic analysis in psychology. Qualitative Research in Psychology, 3(2), 77-101. https://doi.org/10.1191/1478088706qp063 oa

Cifuentes, L., \& Doris Shih, Y. C. (2001). Teaching and learning online: A collaboration between U.S. and taiwanese students. Journal of Research on Computing in Education, 33(4), 456-474. https://doi.org/10.1080/08886504.2001.10 782327

Clandinin, D. J. (2006). Narrative inquiry: A methodology for studying lived experience. Research Studies in Music Education, 27(1), 44-54.

https://doi.org/10.1177/1321103X0602700 10301

Compton, L. K. L. (2009). Preparing language teachers to teach language online: A look at skills, roles, and responsibilities. Computer Assisted Language Learning, 22(1), 73-99. https://doi.org/10.1080/095882208026138 31

Cowie, N. (2011). Emotions that experienced English as a Foreign Language (EFL) teachers feel about their students, their colleagues and their work. Teaching and Teacher Education, 27(1), 235-242. https://doi.org/10.1016/j.tate.2010.08.006

Fairman, J. C., \& Mackenzie, S. V. (2012). Spheres of teacher leadership action for learning. Professional Development in Education, 38(2), 229-246. https://doi.org/10.1080/19415257.2012.65 7865

Febriana, M., Karlina, Y., Nurkamto, J., \& Rochsantiningsih, D. (2018). Teacher Absenteeism in Rural Indonesian Schools. 2, 47-51.

Fogle, L. W., \& Moser, K. (2017). Language Teacher Identities in the Southern United States: Transforming Rural Schools. Journal of Language, Identity and Education, 16(2), 65-79.

https://doi.org/10.1080/15348458.2016.12 77147 
Gigliotti, R. A. (2016). Institutional Identification and Sense of Community: Analysis of a New Online Graduate Public Administration Program. Journal of Public Affairs Education, 22(3), 399-414. https://doi.org/10.1080/15236803.2016.12 002255

Hampel, R., \& Stickler, U. (2005). New skills for new classrooms: Training tutors to teach languages online. Computer Assisted Language Learning, 18(4), 311-326. https://doi.org/10.1080/095882205003354 55

Hansen-Thomas, H., Grosso Richins, L., Kakkar, K., \& Okeyo, C. (2016). I do not feel I am properly trained to help them! Rural teachers' perceptions of challenges and needs with English-language learners. Professional Development in Education, 42(2), 308-324. https://doi.org/10.1080/19415257.2014.97 3528

Hargreaves, A. (2000). Mixed emotions: Teachers' perceptions of their interactions with students. Teaching and Teacher Education, 16(8), 811-826. https://doi.org/10.1016/S0742051X(00)00028-7

Hargreaves, A. (2001a). Emotional geographies of teaching. Teachers College Record, 103(6), 1056-1080. https://doi.org/10.1111/01614681.00142

Hargreaves, A. (2001b). The emotional geographies of teachers' relations with colleagues. International Journal of Educational Research, 35(5), 503-527. https://doi.org/10.1016/S08830355(02)00006-X

Hargreaves, A. (2005). Educational change takes ages: Life, career and generational factors in teachers' emotional responses to educational change. Teaching and Teacher Education, 21(8), 967-983. https://doi.org/10.1016/j.tate.2005.06.007

Hayes, D. (2010). Language learning, teaching and educational reform in rural Thailand: An English teacher's perspective. Asia Pacific Journal of Education, 30(3), 305-319. https://doi.org/10.1080/02188791.2010.49 5843

Howland, J. L., \& Moore, J. L. (2002). Student perceptions as distance learners in internetbased courses. Distance Education, 23(2), 183-195. https://doi.org/10.1080/015879102200000 9196

Iwaniec, J. (2014). Motivation of pupils from southern Poland to learn English. System, 45(1), 67-78. https://doi.org/10.1016/j.system.2014.05.0 03

Iwaniec, J. (2020). The effects of parental education level and school location on language learning motivation. Language Learning Journal, 48(4), 427-441. https://doi.org/10.1080/09571736.2017.14 22137

Jenkins, G. (2020). Teacher agency: the effects of active and passive responses to curriculum change. Australian Educational Researcher, 47(1), 167-181. https://doi.org/10.1007/s13384-01900334-2

Kam, H. W. (2002). English Language Teaching in East Asia Today: An Overview. Asia Pacific Journal of Education, 22(2), 1-22. https://doi.org/10.1080/021887902022020 3

Kayi-Aydar, H. (2015). Multiple Identities, Negotiations, and Agency Across Time and 
Space: A Narrative Inquiry of a Foreign Language Teacher Candidate. Critical Inquiry in Language Studies, 12(2), 137-160. https://doi.org/10.1080/15427587.2015.10 32076

Kormos, J., \& Csizér, K. (2008). Age-related differences in the motivation of learning english as a foreign language: Attitudes, selves, and motivated learning behavior. Language Learning, 58(2), 327-355. https://doi.org/10.1111/j.1467-

9922.2008.00443.x

Kozar, O. (2012). Use of synchronous online tools in private English language teaching in Russia. Distance Education, 33(3), 415-420. https://doi.org/10.1080/01587919.2012.72 3164

Lamb, M. (2012). A Self System Perspective on Young Adolescents' Motivation to Learn English in Urban and Rural Settings. Language Learning, 62(4), 997-1023. https://doi.org/10.1111/j.14679922.2012.00719.x

Lestiyanawati, R., \& Widyantoro, A. (2020). Strategies and Problems Faced by Indonesian Teachers in Conducting ELearning System During COVID-19 Outbreak. Journal of Culture, Literature, Linguistic and English Teaching, 2(1), 71-82.

Liu, Yongcan. (2016). The emotional geographies of language teaching. Teacher Development, 20(4), 482-497. https://doi.org/10.1080/13664530.2016.11 61660

Liu, Yuanyuan, Wang, H., \& Zhao, R. (2020). Teacher agency and spaces in changes of English language education policy. Current Issues in Language Planning, $0(0), 1-19$. https://doi.org/10.1080/14664208.2020.17 91532
Lundin, L. (2020). Online narratives about panic attacks: interpreted within a psychodynamic framework. Social Work in Mental Health, 18(3), 349-365. https://doi.org/10.1080/15332985.2020.17 44500

Miller, E. R., \& Gkonou, C. (2018). Language teacher agency, emotion labor and emotional rewards in tertiary-level English language programs. System, 79, 49-59. https://doi.org/10.1016/j.system.2018.03.0 02

Molla, T., \& Nolan, A. (2020). Teacher agency and professional practice. Teachers and Teaching: Theory and Practice, 26(1), 67-87. https://doi.org/10.1080/13540602.2020.17 40196

Mpahla, N. E., \& Okeke, C. I. O. (2015). The Rurality of Continuing Professional Teacher Development (CPTD). Studies of Tribes and Tribals, 13(1), 22-33. https://doi.org/10.1080/0972639x.2015.11 886708

Pitura, J., \& Terlecka-Pacut, E. (2018). Action research on the application of technology assisted urban gaming in language education in a Polish upper-secondary school. Computer Assisted Language Learning, 31(7), 734-763. https://doi.org/10.1080/09588221.2018.14 47490

Priestley, M., Biesta, G., \& Robinson, S. (2012). Teachers as agents of change: An exploration of the concept of teacher agency. http://www.ioe.stir.ac.uk/events/tacc.php.

Rejeki, S., Kristina, D., \& Drajati, N. A. (2018). SOCIOCULTURAL FRAMEWORK Emotional Geography of a Female EFL Teacher in Rural Area in Indonesia. 2, 52-55. 
Rural Teachers' Perceptions of English Language Teaching in a Virtual Classroom: Love or Hate?

Rogers, R., \& Wetzel, M. M. (2013). Studying Agency in Literacy Teacher Education: A Layered Approach to Positive Discourse Analysis. Critical Inquiry in Language Studies, 10(1), 62-92. https://doi.org/10.1080/15427587.2013.75 3845

Such, B. (2019). Scaffolding English language learners for online collaborative writing activities. Interactive Learning

Environments, 4820. https://doi.org/10.1080/10494820.2019.15 79233

Wigati, I. (2019). Attitudes Towards Learning English : A Comparative Study Of Rural And Urban

Junior. 
Dini Rosita Sari 